\title{
Monetary Policy Surprises in Russia ${ }^{1}$
}

\author{
Alexander Tishin, Bank of Russia \\ tishinav@cbr.ru
}

This paper studies the monetary policy transmission in the Russian economy. The key question of this research is to determine how monetary policy affects the economy through currency exchange rates. I construct a series of monetary policy surprises for the Russian economy using the high-frequency identification approach. Many papers use futures on interest rates as monetary policy instruments; however, we do not have these futures on the Russian financial market. Therefore, I use different currency futures as monetary surprises because these futures are liquid, and they may reveal market sentiments. I take the dates when the Board of Directors of the Bank of Russia made a decision on the key rate and look at the changes in the currency exchange market in a tiny 30-minute window. Next, I construct a structural vector autoregression model to show the effect of these surprises on macroeconomic variables. In the identification process, I use the external instruments approach à la Gertler and Karadi (2015). Finally, I compare the results with other methods (Cholesky decomposition). I find that a tightening monetary policy significantly increases the bond rate; moreover, the effect on inflation is not immediate, but appears after a couple of months.

Keywords: monetary policy transmission, external instruments, high-frequency identification, SVAR, currency futures

JEL Codes: E31, E32, E43, E44, E52, E58
Citation: Tishin, A. (2019). Monetary Policy Surprises in Russia. Russian Journal of Money and Finance, 78(4), pp. $48-70$.

doi: $10.31477 /$ rjmf.201904.48

\section{Introduction}

Since the 90 s, the role of the interest rate as a monetary policy instrument has increased due to central banks switching to interest rate-oriented policies and inflation targeting. Many countries have already long been using inflation targeting. For instance, New Zealand adopted it in 1990, with Canada doing so the following

\footnotetext{
${ }^{1}$ I would like to thank Konstantin Styrin for his helpful comments and suggestions, Valery Charnavoki and Konstantin Egorov for their insightful remarks. All errors are mine.

2 The author is a New Economic School (MAE'19) graduate and winner of the Economic Research Competition for students and postgraduates of Russian universities organised by the Bank of Russia and the Russian Journal of Money and Finance in 2019.
} 
year. A good overview of the history of inflation targeting and the current principles of monetary policy is given in the recent book by Adrian et al. (2018).

Inflation targeting policy means that the Central Bank is extensively using its interest rate instrument to keep inflation around the target level. For example, when the current (or expected) inflation is above the target level, the Central Bank will want to raise its interest rate. In this situation the Central Bank would like to evaluate the effects of monetary policy, i. e. to understand the future response of other economic indicators.

The Bank of Russia switched to a floating exchange rate in late $2014^{3}$ and decided to set a medium-term target for inflation at $4 \%$. Therefore, the role of the key rate increased significantly. This paper aims to evaluate the effects of key rate changes by the Bank of Russia, that is, to quantify the transmission mechanism in the Russian economy. Thus, the main research question is how monetary policy decisions affect the future path of macroeconomic variables.

The motivation for this paper is the following. Firstly, the responses of financial and macroeconomic variables are of interest to the Central Bank since they allow for a more accurate understanding of the impact of monetary policy. Secondly, the major difference from other papers is that I use the currency exchange rate as an indicator of monetary policy surprises. Therefore, the transmission channel through currency may be an alternative way to identify surprises and their effects on the economy. Finally, the identification of monetary policy surprises for Russia has not been thoroughly studied. Evaluating monetary policy in emerging countries may reveal new areas of research.

The contribution of this paper is the following. Firstly, I construct a new series of monetary policy surprises for Russia using high-frequency data on currency instruments such as spot, futures and forward exchange rates. Secondly, I construct a proxy structural vector autoregression (SVAR) à la Gertler and Karadi (2015). My model differs in that I expand it to cover a small open economy by adding variables which are more typical for an open economy such as exchange rate, trade balance, etc.

In the process of writing this paper, I encountered various problems. The Russian financial market does not have a long history. In this comparatively short time horizon, a lot of events occurred: from the crisis in 2008 to the change in monetary policy in 2014. Moreover, investors in the markets hold their own beliefs about the credibility of the Bank of Russia's monetary policy. They also hold beliefs about the future path of monetary policy. Although nowadays the Bank of Russia is trying to pursue a consistent monetary policy, in the early 2000s investors would not have been able to be so confident in its consistency, which could have contributed to the monetary surprises. For some time, one of the usual ways of identifying monetary surprises was the difference between the real key rate announced by the Central Bank and the consensus forecast of the experts. However, this approach does not take

\footnotetext{
${ }^{3}$ See 'On parameters of Bank of Russia exchange rate policy': https://www.cbr.ru/eng/press/PR/?file=10112014_122958eng_dkp2014-11-10T12_26_04.htm
} 
into account a lot of information which is available in the high-frequency financial market and often reveals no surprises when the consensus forecast accurately predicts the actual decision. It can be said that if the decision is predictable, then the futures prices already include these expectations in the price. Thus, when the decisions are published, we should see no surprises. However, the futures market is very volatile and we can still observe some changes around the time of publication.

The structure of this paper is the following. Section 2 contains a review of relevant literature. In Section 3, I present the high-frequency identification (HFI) approach and its theoretical assumptions. It is based on the idea of identifying monetary policy shocks using intraday data in a tight window around a monetary policy event when only the information about this event can influence the market prices.

In Section 4, I present the econometric framework. It is based on the estimation of SVAR models in which I isolate the structural innovation of the variable of interest using the instrumental variables approach. As instruments, I take monetary policy surprises which I identify using HFI.

The most important part of this paper is dedicated to evaluating the impact of the monetary policy of the Bank of Russia. These results are described in detail in Section 5. For Russia, I estimate a baseline model (closed economy model) and a small open economy model. As external instruments, I use spot, futures and forwards exchange rates with different maturity dates.

Section 6 includes two robustness tests. In the first one, I estimate my model with a focus on the period up to the mid-2014. This is the period when the Bank of Russia used a managed floating exchange rate. In the second exercise I 'change' the date of the monetary policy decision. Specifically, I calculate the surprises the day before and the day after the actual day of decision. In this test, I try to understand if the calculated surprises represent actual shocks on the market.

I find that the 1-year government bond rate increases in response to tightening monetary policy. However, this is not the case for the consumer price index (CPI) and the excess bond premium (EBP). These variables show counterintuitive dynamics. When the Bank of Russia raises the key rate, the CPI grows and begins to decline only a few months later. The EBP falls immediately.

Section 7 concludes.

\section{Related literature}

A number of papers have already used the HFI strategy in the process of evaluating monetary policy surprises. This approach is first used in the paper by Kuttner (2001), where the author uses the current-month (spot) federal funds futures contract (FF1) to measure the monetary policy surprises around the Federal Open Market Committee (FOMC) meeting day. He finds that for anticipated federal funds rate changes there is a very small response, while for unanticipated ones the response is high and statistically significant. 
Another seminal paper by Romer and Romer (2004) uses a narrative approach to monetary policy surprises together with 'Greenbook' forecasts to construct surprises which are independent of the future information. They find significant responses in inflation and unemployment.

A further interesting paper is that of Gürkaynak et al. (2005), with the key difference from the previous papers being that the authors use a set of instruments in the process of shock identification. They use returns of the current month's federal funds futures (FF1), the three-month ahead federal funds futures (FF4), and the six-month, nine-month and year ahead futures on Eurodollar deposits (ED2, ED3, ED4) on the days of the FOMC decision announcement. They find that monetary policy statements and monetary policy actions have a different effect on the financial market. Many authors continue to develop this approach, for example, Swanson (2017) studies the effect of forward guidance and largescale asset purchases during 2009-2015. Also, there are studies on monetary policy surprises in countries other than the USA or Europe. For example, Pescatori (2018) examines the monetary policy communications by the Central Bank of Chile. He finds that forward guidance is an effective tool in monetary policy, and that tightening monetary policy leads to a decline in the economy, which corresponds to findings in other papers.

The most famous paper about the HFI is by Gertler and Karadi (2015). In their paper the authors use three-month ahead federal funds rate futures. These futures include market expectations about the future path of the target rate. The authors find significant responses in output and inflation in SVAR models. Moreover, they show that forward guidance is an important tool for modern monetary policy. Similar work was done for the UK by Cesa-Bianchi et al. (2016). They adapt this framework to a small open economy model, constructing monetary policy surprises for the UK. The authors find that a rise in the interest rate leads to a slowdown in economic activity and an appreciation of the nominal exchange rate.

Many researchers try to work with economic forecasts and market expectations. Nakamura and Steinsson (2018) build a model in which the Fed can affect markets' beliefs not only about the future path of monetary policy but also about other macroeconomic variables, hence making forward guidance an important monetary policy tool. Justiniano et al. (2012) show that forward guidance helps the Fed to commit to keeping interest rates at zero levels for a longer time. Cieslak and Schrimpf (2019) show that non-monetary news also plays an important role in the Central Bank's communications, because financial markets react to this non-monetary news.

Finally, literature on measuring monetary policy shocks is currently developing. Zhang (2018) finds that the previous measure of monetary policy surprises has positive correlation with the Blue Chip forecast of inflation and negative correlation with the Blue Chip unemployment forecasts. This correlation is counter-intuitive because when the FOMC raises the federal funds rate they 
are signalling to the market that inflation is above the stationary level and unemployment is below. The author proposes a new measure of monetary policy surprises, which demonstrates a correct correlation with these indicators.

Moreover, the method for identifying the shocks using the external instruments introduced by Gertler and Karadi (2015) assumes that the coefficients in the model are constants. However, if we consider a long period, there is a high probability that the principles of monetary policy have changed. The next step in the estimation of this kind of models involves using time-varying parameters. For instance, Paul (2019) uses high-frequency surprises together with time-varying parameter vector autoregression (TVP-VAR) to evaluate the impact of monetary policy on asset prices and economic variables (such as stocks and house prices, CPI, industrial production (IP), etc). The author finds that the effects of monetary policy are not stable over time.

\section{High-frequency identification}

This paper is based on two important issues: HFI and SVAR. In this section, I discuss the process of HFI, and in the next section, I discuss the SVAR framework.

I construct monetary policy surprises using intraday and daily data. The high-frequency approach to identification looks at the changes in small intervals similar to Gertler and Karadi (2015). I define monetary policy surprises as:

$$
\begin{gathered}
s_{m}=\frac{p_{m+20}-p_{m-10}}{p_{m-10}}, \\
s_{d}=\frac{p_{d}-p_{d-1}}{p_{d-1}},
\end{gathered}
$$

where $s_{m / d}$ is a measured surprise, the subscript $d$ refers to the daily data, $m$ refers to the intraday data, $p_{m / d}$ is the price of the asset in the day $d$ or in the minute $m$. Thus, in other words, using the intraday data, I identify a monetary policy surprise as the asset returns in a 30-minute window: 10 minutes before the monetary policy event and 20 minutes after this event. Some authors, for example, Ferrari et al. (2016), average prices in this interval. Using the daily data, I identify surprises as the daily asset returns at the end of the event's day compared to the previous day.

These monetary policy surprises should show the unanticipated changes in the markets as described in Cesa-Bianchi et al. (2016), namely:

$$
\begin{aligned}
& s_{t}=\epsilon_{t}^{m p}+v_{t}, \\
& \mathbb{E}\left[v_{t} \mid \epsilon_{t}^{m p}\right]=0,
\end{aligned}
$$

where $\epsilon_{t}^{m p}$ is the true monetary policy surprise and $v_{t}$ is a noise. 
These equations mean that I measure surprise $s_{t}$ with some random error $v_{t}$ which is independent of the true monetary policy shock $\epsilon_{t}^{m p}$. Therefore, there are two very important assumptions (Cesa-Bianchi et al., 2016) in this process of identification:

1. $\mathbb{E}\left[v_{t} \mid x\right]=0$ - the background noise is independent of the state of macro economy $(x)$ for any $t$.

2. $\operatorname{Var}\left[v_{y}\right] \simeq 0$ - the probability of this shock happening is very small (measure zero shock).

Unfortunately, this paper does not include any formal test of these assumptions (for example, a test of overidentifying restrictions). However, there is an economic intuition behind these assumptions. Starting with the first one, the intuition is that the HFI approach helps to isolate the monetary policy shock from all others in the tiny 30-minute window the only significant news on the markets is about the monetary policy decision. This logic is less applicable to the daily data because the markets have access to a lot of news during the business day. Nevertheless, if we look at the relevance of different financial news, monetary policy news will always be very important. For example, in Thomson Reuters Eikon, news about monetary policy decisions is marked as highly important. Therefore, I can assume that if I measure a daily surprise, I still measure monetary policy surprise but, probably, with a higher noise level when compared to the intraday data.

Let us turn to the second assumption. It concerns the likelihood of a shock. I assume that when I measure the monetary policy shock, the probability of other shocks is very small. Choosing a small window is also helpful in this situation. When I look at the events in a 30-minute window, it is less likely that another event will occur. This is less true for daily data, but it is still possible to use this assumption.

\section{Econometric framework review}

In this section, I describe the econometric framework, which I use to evaluate the transmission mechanism. In this section, I will be guided by Cesa-Bianchi et al. (2016) and Kilian (2011). I estimate the SVAR model using external instruments to isolate monetary policy innovations. This approach is quite common in modern literature.

This identification strategy implies that I obtain the estimated residuals from the reduced form vector autoregression (VAR), then use the instrumental variables (IV) approach to estimate the matrix of coefficients of innovations in the structural form and, finally, compute impulse response functions $(\mathcal{J} \mathcal{R} \mathcal{F}$ s). For longer horizons, I can iterate $\mathcal{J} \mathcal{R} \mathcal{F}$ s. The process is described in more detail below.

Let us consider the following SVAR model and its reduction:

$$
\begin{gathered}
A Y_{t}=B Y_{t-1}+C \epsilon_{t}, \\
A^{-1} A Y_{t}=A^{-1} B Y_{t-1}+A^{-1} C \epsilon_{t},
\end{gathered}
$$




$$
\begin{gathered}
Y_{t}=D Y_{t-1}+F \epsilon_{t}, \\
Y_{t}=D Y_{t-1}+u_{t},
\end{gathered}
$$

where $Y_{t}$ is $(m \times 1)$ the vector of endogenous variables, $\mathrm{D}$ is $(m \times m)$ the matrix of reduced form coefficients, $\epsilon_{t}$ is structural innovations, $u_{t}$ is $(m \times 1)$ the reduced form error term. The aim is to find the matrix $F$. Note that the matrix $A$ can be an identity. Moreover, we know that $\sum_{\epsilon}=I, \sum_{u} \neq I$.

Note that, the equation (8) is called the reduced form VAR. Also, we know that any $\operatorname{VAR}(p)$ model can be written in the form of $\operatorname{VAR}(1)$. So, these simplifications do not play an important role.

Further, let us divide the $Y_{t}$ variables into the variable of interest, for example, $p_{t}$ and the other variables $X_{t}$ :

$$
Y_{t}=\left(\begin{array}{l}
p_{t} \\
X_{t}
\end{array}\right)=\left[\begin{array}{ll}
d_{11} & D_{12} \\
D_{21} & D_{22}
\end{array}\right]\left(\begin{array}{l}
p_{t-1} \\
X_{t-1}
\end{array}\right)+\left[\begin{array}{ll}
f_{11} & F_{12} \\
F_{21} & F_{22}
\end{array}\right]\left(\begin{array}{c}
\epsilon_{t}^{p} \\
\epsilon_{t}^{X}
\end{array}\right),
$$

where $d_{11}$ and $f_{11}$ are scalars, $D_{12}$ and $F_{12}$ are $(1 \times m-1)$ vectors, $D_{21}$ and $F_{21}$ are $(m-1 \times 1)$ vectors, $D_{22}$ and $F_{22}$ are $(m-1 \times m-1)$ vectors, $\epsilon_{t}^{p}$ is the structural innovation which is linked to the variable of interest and $\epsilon_{t}^{X}$ are the structural innovations of other variables.

Now we can find the $\mathcal{J R F}$ s, as derivative with respect to the innovations and then iterate to find $\mathcal{J} \mathcal{R} \mathcal{F}$ s for $n$-step.

$$
\begin{gathered}
{\left[\begin{array}{c}
\mathcal{J} \mathcal{R F}_{0}^{p} \\
\mathcal{J} \mathcal{F F}_{0}^{X}
\end{array}\right]=\left[\begin{array}{l}
f_{11} \\
F_{21}
\end{array}\right] \Rightarrow} \\
{\left[\begin{array}{c}
\mathcal{J} \mathcal{R F}_{0}^{p} \\
\mathcal{J} \mathcal{R F}_{0}^{X}
\end{array}\right]=\left[\begin{array}{c}
1 \\
F_{21} \\
f_{11}
\end{array}\right] \Rightarrow} \\
{\left[\begin{array}{c}
\mathcal{J} \mathcal{R F}_{n}^{p} \\
\mathcal{J} \mathcal{R F}_{n}^{X}
\end{array}\right]=D^{n-1}\left[\begin{array}{l}
\mathcal{J} \mathcal{R F}_{n-1}^{p} \\
\mathcal{J} \mathcal{F F}_{n-1}^{X}
\end{array}\right], \text { для } n=2, \ldots, N .}
\end{gathered}
$$

Note that to find the $\mathcal{J} \mathcal{R} \mathcal{F}$ s for one variable $\epsilon_{t}^{p}$, one does not need to estimate all coefficients in $F$, but needs only the first column.

To find $\mathcal{J} \mathcal{R} \mathcal{F}$ s I need to obtain $f_{11}, F_{21}$ and $D$. To estimate $D$ I just estimate the reduced form VAR and find the matrix of estimated coefficients $\hat{D}$. However, there is a more sophisticated way to estimate $f_{11}$ and $F_{21}$. I use the external instruments approach here.

Let us assume that I have an instrument $Z_{t}(z \times 1), z \leq m$. The instrument's number of observations $z$ can be less than the number of observations $m$, even in this case, we can estimate $f_{11}$ and $F_{21}$. 
A good instrument should satisfy two conditions. Firstly, it should be correlated with the variable which I estimate $\left(\epsilon_{t}^{p}\right)$. Secondly, it should be uncorrelated with all the other shocks $\left(\epsilon_{t}^{X}\right)$.

$$
\begin{aligned}
& \mathbb{E}\left[\epsilon_{t}^{p} Z_{t}\right] \neq 0, \\
& \mathbb{E}\left[\epsilon_{t}^{X} Z_{t}\right]=0 .
\end{aligned}
$$

However, I do not observe the structural $\epsilon_{t}$, I can only estimate $\hat{u}_{t}$. Nevertheless, I know that $D \epsilon_{t}=u_{t}$, therefore, $u_{t}$ is a kind of measure of true $\epsilon_{t}$, then I can use twostage least squares (2SLS) of $u_{t}^{X}$ on $u_{t}^{p}$ using instruments $Z_{t}$. To do so, I estimate the reduced form model, obtain estimated residuals $\hat{u}_{t}$ and use them in 2SLS:

$$
\widehat{u}_{t}^{p}=\beta Z_{t}+\mu_{t}
$$

to obtain the estimated values $\overline{\hat{u}}_{t}^{p}$ and then regress $\hat{u}_{t}^{x}$ on $\overline{\hat{u}}_{t}^{p}$ to find the $\frac{\hat{F}_{21}}{f_{11}}$ :

$$
\hat{u}_{t}^{X}=\frac{F_{21}}{f_{11}} \overline{\hat{u}}_{t}^{p}+\eta_{t} \text {. }
$$

Finally, when I estimate $\frac{\hat{F}_{21}}{f_{11}}$ and $\hat{D}$, I can easily obtain $\mathcal{J} \mathcal{R} \mathcal{F}$ s as shown in equations (11) and (12). The logic behind this identification scheme is the following. I use external data to estimate the structural parameters of the VAR model. In this way, I try to capture the exogenous variation of a monetary policy shock.

\section{Monetary policy surprises in Russia}

In this section, I discuss the analysis in regards to Russia. The financial market in Russia is very different from the USA. Despite the importance of monetary policy in Russia, we do not have Liquid Instruments For the Interest rate. The closest instruments are MIACR (monthly average actual rates on Moscow banks' credits) and MosPrime (Russian ruble deposits rate). However, these rates are only calculated on a daily basis and serve mainly for indicative purposes. Moreover, futures on these rates are very illiquid. Therefore, I need to measure monetary policy surprises through other existing instruments.

\subsection{Data}

I estimate the SVAR model with a focus on the period from December 2002 to October 2018. The starting point is chosen due to the earliest data availability. These time series include several important events: two crises, in 2008 and 2014, and the change of the Bank of Russia exchange rate policy. I discuss these issues later. 


\subsubsection{Monetary policy events}

I obtain the dates of the Board of Directors of the Bank of Russia policy meetings from 2008 to 2018 from the official site (Bank of Russia, 2018). There are about 100 meetings. Furthermore, the monetary policy of the Bank of Russia needs a detail discussion.

The Bank of Russia does not have a long history; ${ }^{4}$ however, it has undergone several stages of modern monetary policy formation. From 1999 to 2014, the Bank of Russia used a managed floating exchange rate regime. It was necessary to smooth unexpected shocks on the Russian economy. Over time, the exchange currency band widened, and on August 2014 its width was 9 rubles. From 10 November 2014, the Bank of Russia switched its exchange rate policy to a fully flexible exchange rate.

As for monetary policy events, the Bank of Russia only posts press releases about monetary policy decisions and publishes the monetary policy report later on the same day. Since 2014 the Bank of Russia has posted its decision at 13:30 $(\mathrm{GMT}+3)$. This is a new practice for the Bank of Russia: before 2014 the publication of monetary policy decisions was chaotic, and was not systematic in the early years. This may be a possible source of the problem described later in this paper.

\subsubsection{Instruments}

I use Thomson Reuters Datastream (Datastream, 2018) to obtain FX and forwards rates, I use the intraday data from Finam (Finam, 2018) to find futures prices for monetary policy surprises. I also use data from Moscow Exchange for the monthly SVAR (Moscow Exchange, 2018).

Since the Russian financial market is much smaller than that of the US and we do not have derivatives on the interest rate, I try to obtain monetary policy surprises from the currency markets, namely, USD/RUB spot rate, forward rate and futures. Additionally, I use index-linked instruments, namely, MOEX and RTS futures. I choose these instruments because of their liquidity.

Moreover, I use macroeconomic data from Thomson Reuters Datastream and the Russian statistical agency (Federal State Statistic Service, 2018) for key macroeconomic variables, and from the IMF (International Monetary Fund, 2017) for the world economic indicators like oil prices.

The key difference in my data is that as the EBP I take a spread between the clean price of government bonds and corporate bonds. The clean price is the price of the bond minus accrued interest. In the original paper by Gilchrist and Zakrajšek (2012), the authors clean this spread from default premia. This 'cleaning' is not an obvious exercise and, unfortunately, outside of the scope of this work; therefore, I use the EBP with default premia.

\footnotetext{
${ }^{4}$ The History of the Bank of Russia FX policy is available at: http://cbr.ru/eng/DKP/exchange_rate/fx_policy_hist/
} 
Finally, choosing the variables for the small open economy framework is also not an easy task. This choice is based on the paper by Cesa-Bianchi et al. (2016) and, also, I add new variables like oil prices and volatility index as exogenous variables.

The most liquid futures on the Russian financial market are the currency futures and the stock market index futures. For futures, I use both daily and intraday data. You can see the amounts of trades for one day in Table 1 (January 2019). The second important source of instruments is also linked to the currency - FX and forward exchange rates. The important difference between FX rate and futures (forwards) is that the price of futures may account for investors' expectations about future events; however, the FX rate is a spot price for today.

Table 1. Amounts of trades of futures

\begin{tabular}{lll} 
Contract & Volume of trades, contracts & Number of transactions \\
\hline Futures (total) & $\mathbf{3 , 5 1 1 , 2 4 9}$ & $\mathbf{6 6 4 , 3 9 1}$ \\
\hline RTS-3.19 (RTS futures ) & 244,430 & 108,540 \\
\hline MIX-3.19 (MOEX futures) & 19,597 & 11,902 \\
\hline Si-3.19 (USD/RUB futures) & $1,270,586$ & 251,340 \\
\hline Eu-3.19 (EUR/RUB futures) & 71,033 & 20,062 \\
\hline
\end{tabular}

Note: the expiration date of these futures is March 2019.

Source: Moscow Exchange (2018)

In this paper, I construct monetary policy surprises for Russia using spot and futures (forwards) rates. The construction of these surprises is the same as described in Section 3. I measure 30-minute asset returns (or one-day returns) around the monetary policy decision, then I aggregate it to monthly surprises, if I have more than one surprise in one month, I sum them up. If I do not have a surprise in the current month, I assign this month zero. For example, Figure 1 shows the surprises obtained using 1) USD/RUB spot price, and 2) USD/RUB three-month ahead futures. Both are calculated using daily data.

Figure 1. Monetary policy surprises for Russia

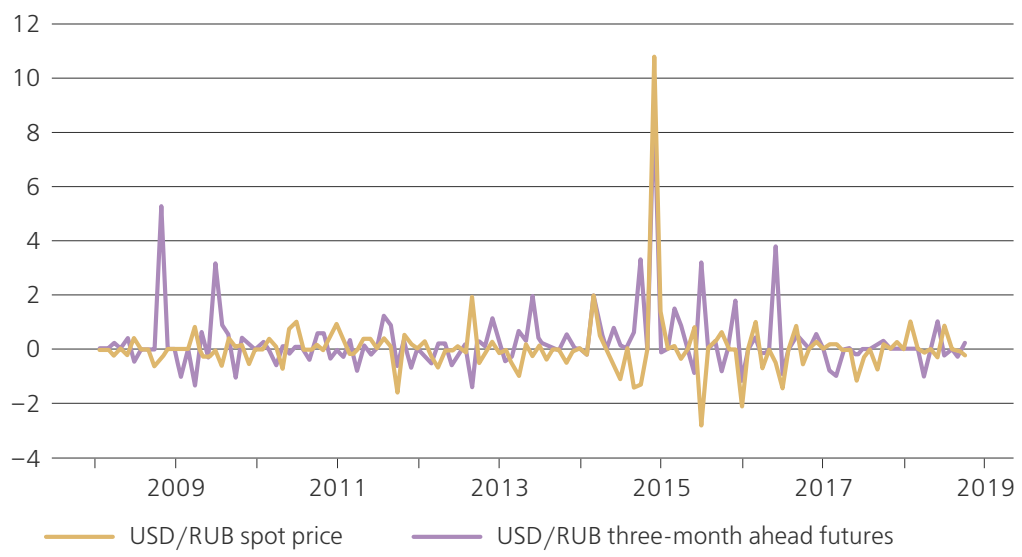


We see a huge spike at the end of 2014. This was the day when the Board of Directors of the Bank of Russia decided to raise the key rate to $17 \%$. Is was on 16 December 2014. The volatility of USD/RUB futures is higher than FX rates. Also, for some dates, the obtained shock has the opposite direction as compared to FX rates. We see that sometimes spot and futures returns go in opposite directions. From my point of view, investors in the market have changed their expectations about the future path of monetary policy and include these expectations in the futures' price while the spot price shows only the price for today's deal.

Figure 2. Minutes surprises

(a) Surprise on 14 September 2018 , raise by $0.25 \%$, new rate is $7.5 \%$

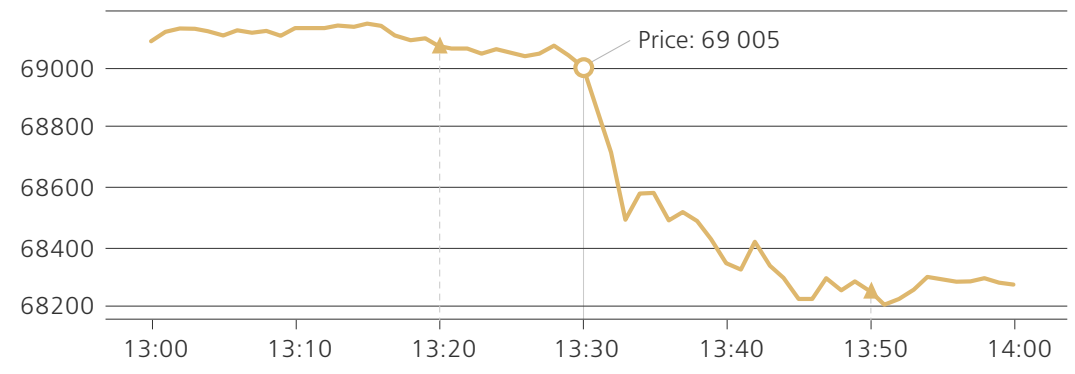

(b) Surprise on 10 June 2016 , cut by $0.5 \%$, new rate is $10.5 \%$

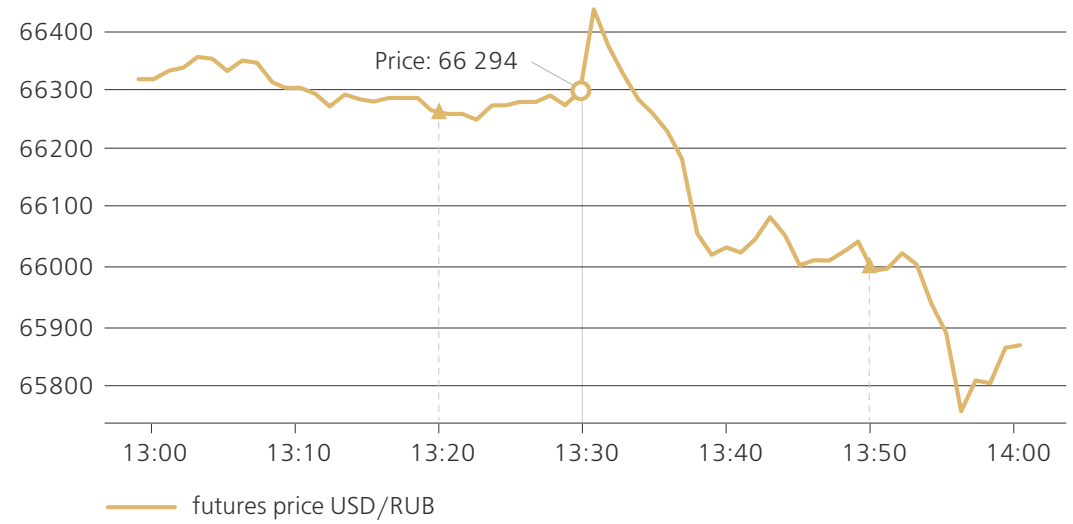

It can be argued that the decisions of the Bank of Russia are very predictable. Especially one day before the meeting and even more so 10 minutes beforehand. If that statement is true, then prices should adjust the moment the market understands the future policy decision. In other words, the price should noticeably change before the meeting, and in the day or minutes surrounding the meeting we should see no changes. In Figure 2 you can see a few selected dates of meetings of the Board of Directors. I show the prices for three-month ahead USD/RUB 
futures. In these figures, the round point indicates the time the decision about the key rate went public. The left triangle point indicates the price 10 minutes before the report publication, and the right triangle point indicates the price 20 minutes after the decision publication. For both figures, we see that the price line before the announcement is practically flat while after the publication it begins to fluctuate. This may tell us that there is some reaction to key rate changes in the Russian financial market.

\subsection{Results}

Russia's small open economy status necessitates adjustments to the estimation of the VAR models. Nevertheless, I start the estimation with a baseline model, the same as Gertler and Karadi (2015) used for the US and expand it to an open economy model using the ideas from Cesa-Bianchi et al. (2016), adding Russiaspecific variables like oil prices and the Russian volatility index (RVI).

All baseline SVAR models were estimated at the same time interval from December 2002 to October 2018. I do not exclude periods of crises, like 2008 or 2014. The baseline SVAR always include 12 lags plus a constant, and it can help capture the non-immediate effect of transition mechanism, for example, the reaction of CPI to changes in monetary policy can only occur after a couple of months.

Then, I estimate small open economy specifications. I use data from January 2006 to October 2018 and I include either 2 or 8 lags, depending on the specification (see Section 5.2.2). This lag reduction is due to the 'short' time series that I have for the Russian economy. When I go to the small open economy model, the number of coefficients grows rapidly; therefore, I need to reduce the number of lags.

All $\mathcal{J} \mathcal{R} \mathcal{F}$ s show the effect of the tightening monetary policy; specifically, $\mathcal{J} \mathcal{R} \mathcal{F}$ s show the effect of a 25 bps interest rate increase. I always use only one instrument, which is specified in the figure title. The dash-line represents $95 \%$ bootstrapped confidence intervals using the wild bootstrap approach.

To estimate SVAR models I use Matlab software with the VAR toolbox by Cesa-Bianchi (2015). For each VAR I report the value of the F-statistic from the first step and the values of information criteria. According to Stock and Yogo (2005) for a good instrument the F-statistic from the first step should be greater than 10. For information criteria, there is also a simple rule: the lower the value the better. However, we can compare models with the same set of $y$ variables.

In the baseline model I use the one-year government bond rate, the log of the CPI (index, $2010=100$ ), the log of the IP (index, $2010=100$ ), and the EBP. I do not use any exogenous variables. For the open economy model I add (in different specifications) real and nominal effective exchange rates, export and import volumes, trade balance as the difference between export and import, 
oil prices and RVI as the index for the volatility of the financial market. In some specifications I also add oil prices and volatility index as exogenous variables. Moreover, I use some of these series in levels (CPI, IP), which can raise questions about stationarity. Stock and Watson (2016) note that in this case one obtains cumulative $\mathcal{J} \mathcal{R} \mathcal{F}$ s. To save space I will not show all the models because they demonstrate more or less the same results.

\subsubsection{Closed economy}

Let us discuss the results of the baseline model in detail. In Figure 3 you can see Cholesky decomposition (3a) and the external instrument identification approach (3b) where the spot USD/RUB rate is used as an instrument.

Figure 3. Baseline model, Cholesky and USD/RUB FX

(a) Cholesky decomposition
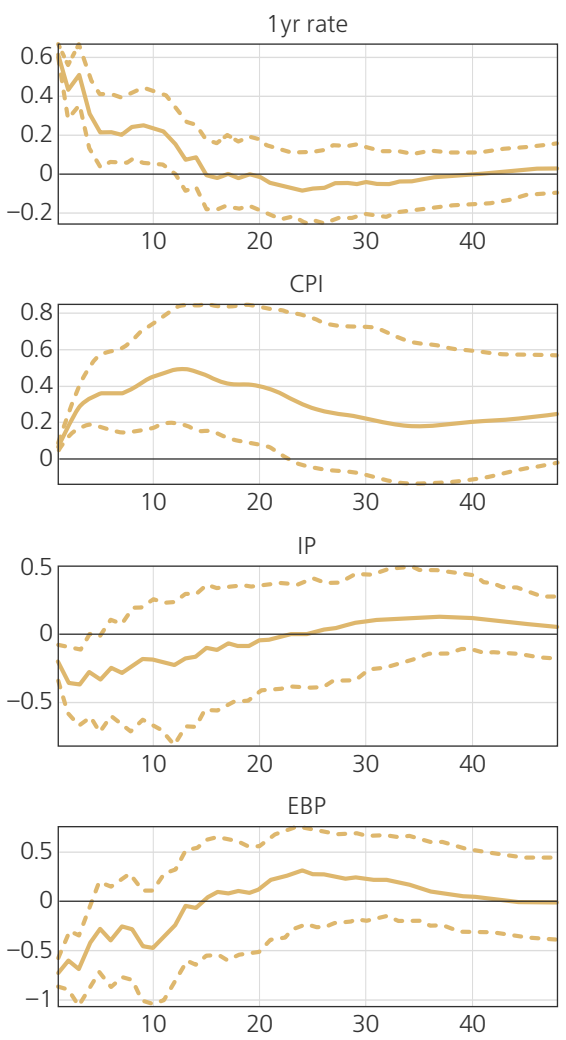

(b) USD/RUB FX
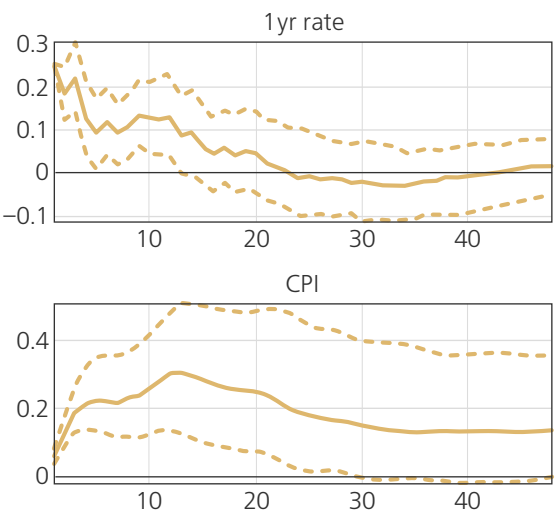

IP
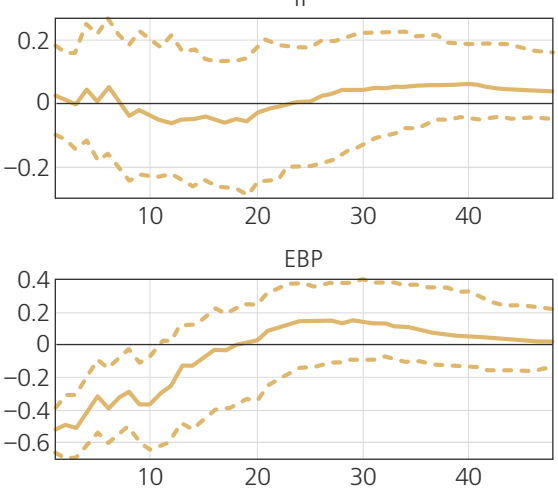

First stage regression, F-stat: 32.21

BIC: -307.69

AIC: -314.05 
Figure 4. Baseline model, USD/RUB three-month futures, minute and daily data

(a) Munite surprises
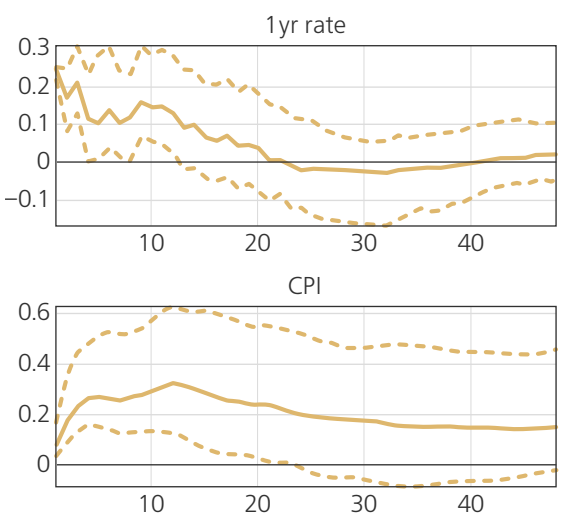

IP
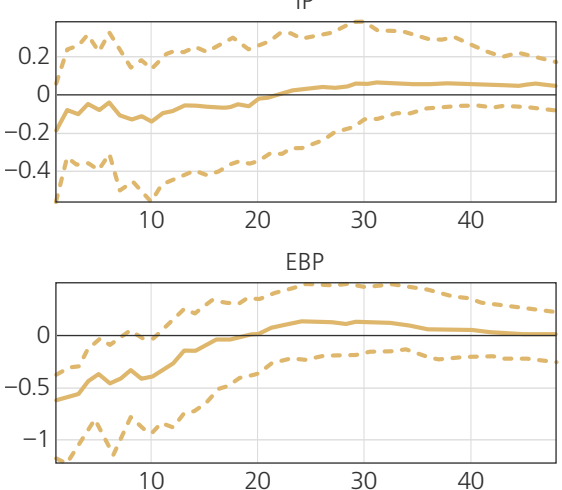

First stage regression, F-stat: 6.54

BIC: -268.98

AIC: -274.89 (b) Daily surprises
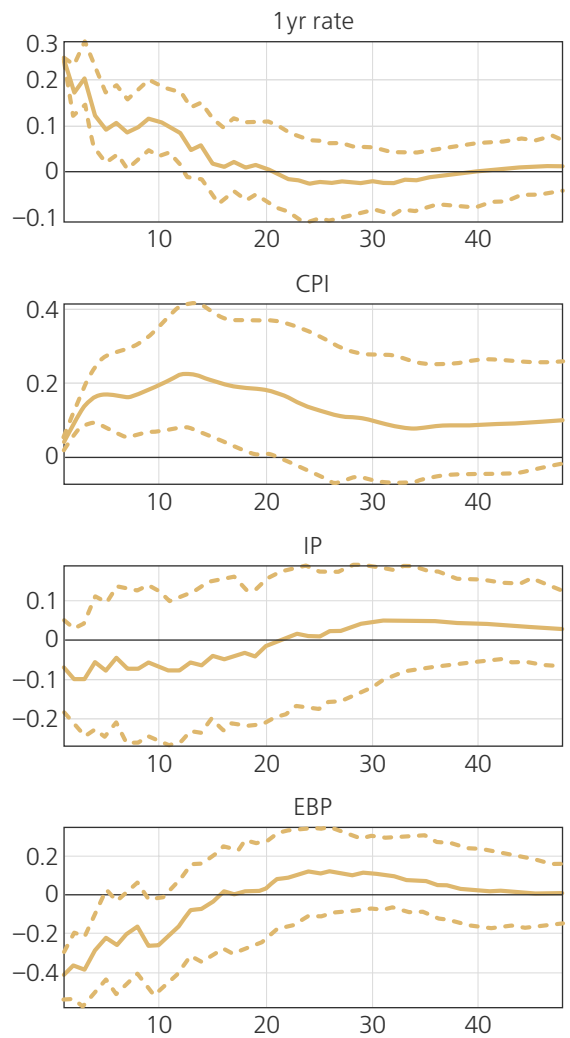

First stage regression, F-stat: 40.93 BIC: -300.39 AIC: -306.75

In contrast to the results for the USA (Gertler and Karadi, 2015), both types of identification show practically the same results. We see a strong and statistically significant increase in one-year government bond rate. The CPI shows the inverse $U$-shape formed statistically significant response, i. e. in the beginning it increases and afterwards it falls. The EBP falls, and it is statistically significant. Effect on the IP is insignificant. The F-statistic from the first step is 32 , which is high.

However, these results are counterintuitive. The movements of macroeconomic variables do not coincide with the theory. For example, if inflation is above the target level, then the Central Bank will want to raise the key rate. Therefore, we expect inflation to fall. However, it increases for approximately a year after a contractionary shock. 
Figure 5. Baseline model, forwards and futures

(a) EUR/RUB three-month forward
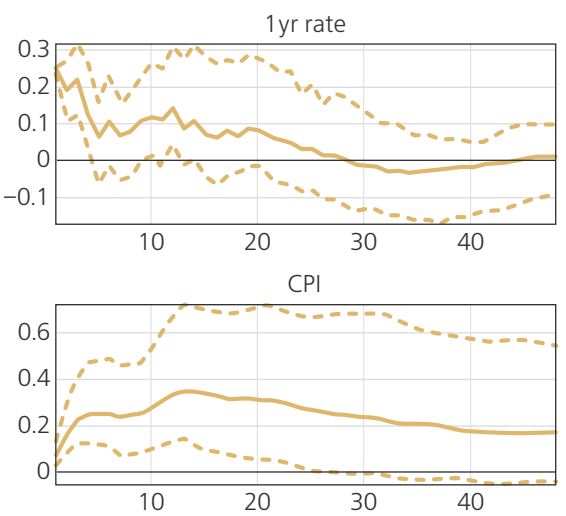

IP

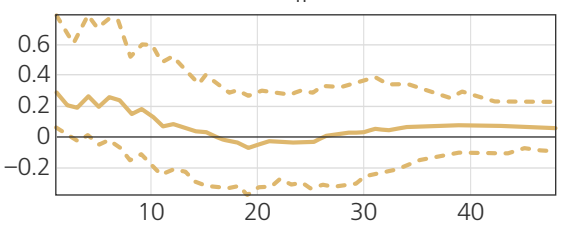

EBP

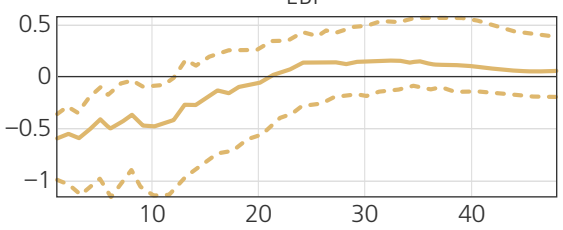

First stage regression, F-stat: 5.42

BIC: -195.81

AIC: -201.25 (b) EUR/RUB three-month futures
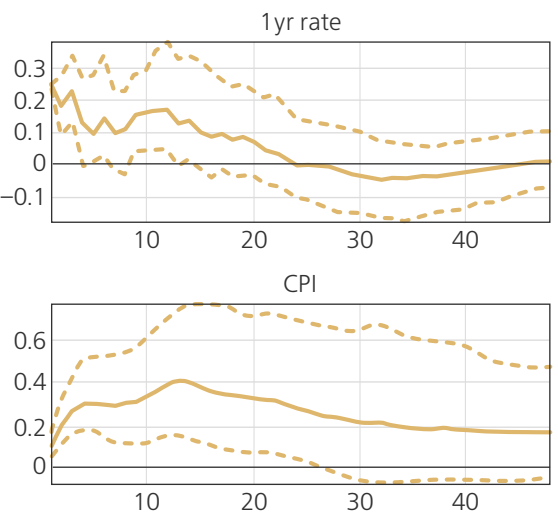

IP

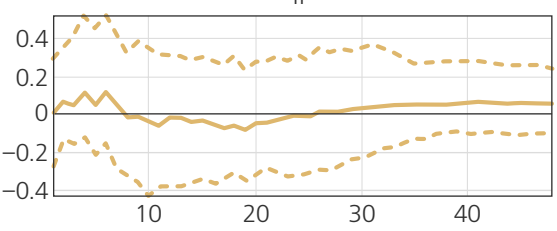

EBP

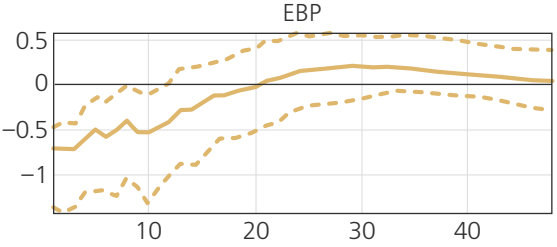

First stage regression, F-stat: 9.68 BIC: -191.76 AIC: -197.19

The problem may lie in my usage of daily FX rates. The latter indicate spot prices and therefore might less likely include information about future events. However, even if I use USD/RUB three-month ahead futures as the external instruments, the results do not change much.

In Figure 4 you can see the $\mathcal{J} \mathcal{R} \mathcal{F}$ s computed using intraday data (4a) and using daily data (4b) futures. Intraday data do not improve the results. For intraday data, the F-statistic is only 6.54, which indicates a weak instrument. Moreover, these results are very sensitive to the choice of window. For example, if I take a 20 -minute window (10 minutes before and 10 minutes after the meeting), the results are even worse. Furthermore, the larger the window size I take, the better results I obtain. For example, when using the daily window the F-statistic is more than 40. Moreover, the $\mathcal{J} \mathcal{R} \mathcal{F}$ s show the same movement as in the previous case. 
Finally, let us compare the futures and forwards as instruments. In Figure 5 you can see the $\mathcal{J} \mathcal{R F}$ s for EUR/RUB three-month forwards (5a) and EUR/RUB three-month futures (5b). As in both previous cases, we see the same movements. CPI significant grows and then declines. The EBP statistically significant drops. The one-year government bond rate increases. The F-statistic is about 10 for futures and about 5 for forwards and much smaller than for USD/RUB FX and futures rates. The other instruments do not show any better results.

\subsubsection{Open economy}

Now, let us turn to the small open economy framework. In this section, I also estimate different specifications of the models; all of them show more or less the same results. Below I show the most interesting examples.

Figure 6. Open economy model, USD/RUB FX, 2 lags
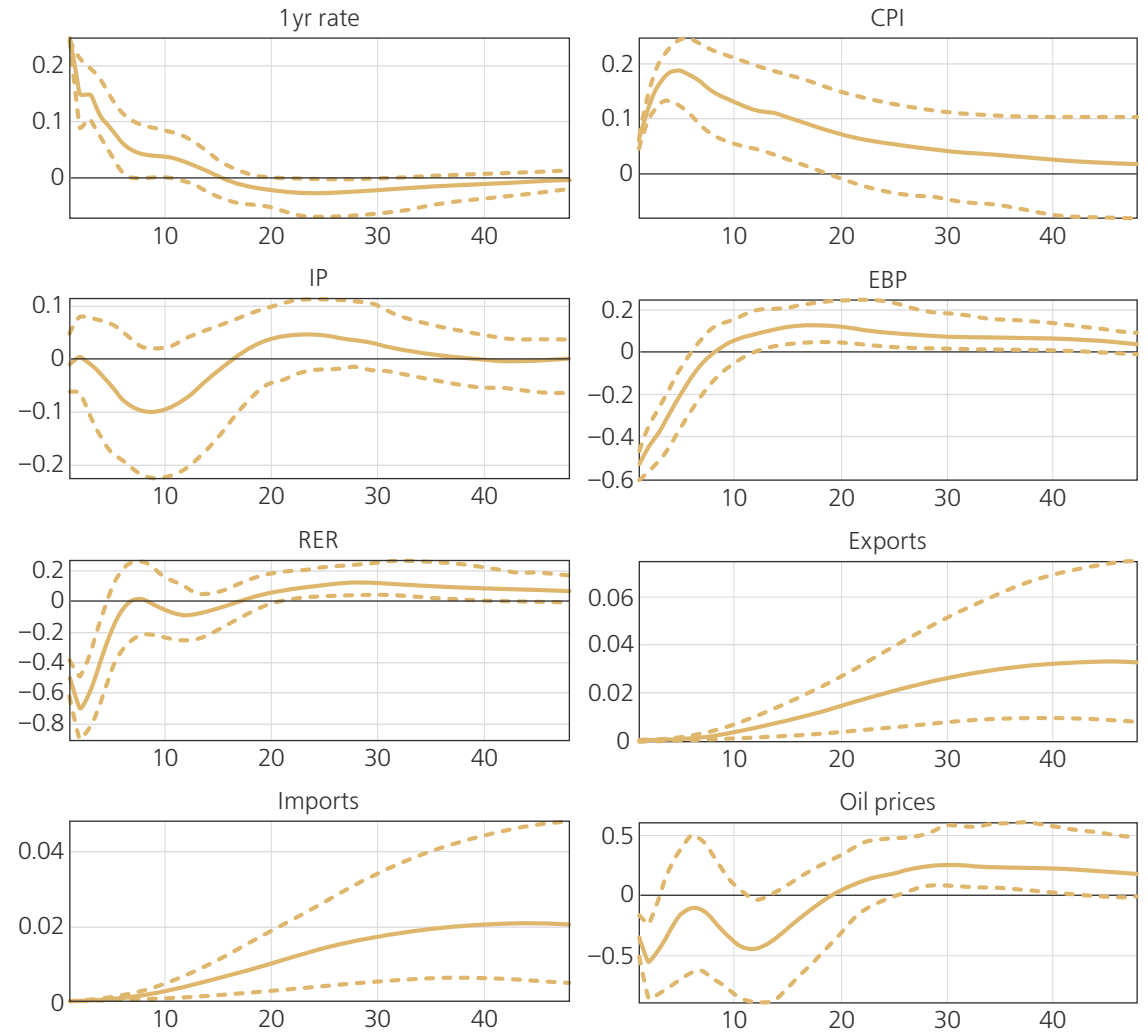

First stage regression, F-stat: 35.63

BIC: -350.11

AIC: -356.48 
As new open economy variables, I add real (RER) and nominal (NER) effective exchange rates (index, 2010=100), export and import volumes (index, $2010=100$ ), and their difference as a trade balance. I use oil prices (spot price) and the RVI in some specifications as Russia's specific variables. Note that the RVI index is a new instrument on the Russian financial market. It was only introduced in 2013, before it there was the RTSVX index. The RTSVX is the RTS volatility index; it was calculated from 2006 to 2013. In this paper, I combine both indices in one to obtain longer time series. Further, I will call this 'artificial' RVI index for simplicity. All these series are on a monthly basis, seasonally and inflation adjusted if needed.

In Figure 6 you can see the results where I use the RVI as exogenous and oil prices as endogenous variables. Here, I use only two lags. This figure clearly shows the problem of a 'short' time series. We see that the confidence intervals for the VAR with two lags is considerably smaller and the lines are smoother, but we lose, probably, important information if the connection between variables occurs more than in two months.

Nevertheless, the $\mathcal{J} \mathcal{R} \mathcal{F}$ s are very similar to the closed economy case. Government bond rates increase are statistically significant. The CPI increases and then declines, and the effect is also statistically significant. The EBP and the RER both statistically significantly decline. Export and import start to grow only after eight months. The F-statistic from the first step is still high. Moreover, exogenous oil prices have a noticeable impact on the Russian economy. Also, we can reduce dimensionality if we combine export and import as the trade balance (their difference).

In Figure 7 you can see the results for the RVI and oil prices as exogenous variables. We see that at least two variables have changed their responses. Now the effect on the IP shows a sinusoidal-monotonous character, i.e. it combines periods of growth and decline, but turns out to be insignificant. The effect on the $\mathrm{CPI}$ has also changed. For the baseline specification, I obtain an inverse U-shape curve. However, for the open economy framework, the decline in the CPI happens much earlier than in the baseline model and this decline is steeper. This effect can support the idea that the reaction of the CPI to tightening monetary policy occurs only a few months after the surprise.

On the one hand, it may be caused by high inflation at the end of 2014 and the beginning of 2015 when the Bank of Russia had raised the key rate. On the other hand, it may show forward guidance in monetary policy. The Bank of Russia raises the key rate not because of high inflation today but due to predicting high inflation in the future. Moreover, we see that the RER is depreciating the moment the interest rate decision is made. Trade balance does not show any responses in approximately ten months and then starts to improve.

The open economy framework slightly improves the results from a theoretical point of view. For example, the responses of the CPI can be explained 
better. For instance, when the Central Bank raises the key rate, the transmission is not instant. Inflation increases for a few months after the shock and then starts to decrease.

However, there are still many problems here. For example, the EBP demonstrates the wrong response. The problem with the EBP may be linked with the wrong calculation method. Gilchrist and Zakrajšek (2012) remove the default premia from their EBP. In my case, the EBP still has the default premia.

The monetary policy surprises also do not give us confidence about the results. The 30-minute surprises show the worst results while daily USD/RUB spot rates perform quite well. Moreover, many $\mathcal{J} \mathcal{R} \mathcal{F}$ s are very similar to those in Cholesky decomposition. It may be the source of inconsistency of my results.

Figure 7. Open economy model, USD/RUB FX, 8 lags, oil prices and RVI as exogenous
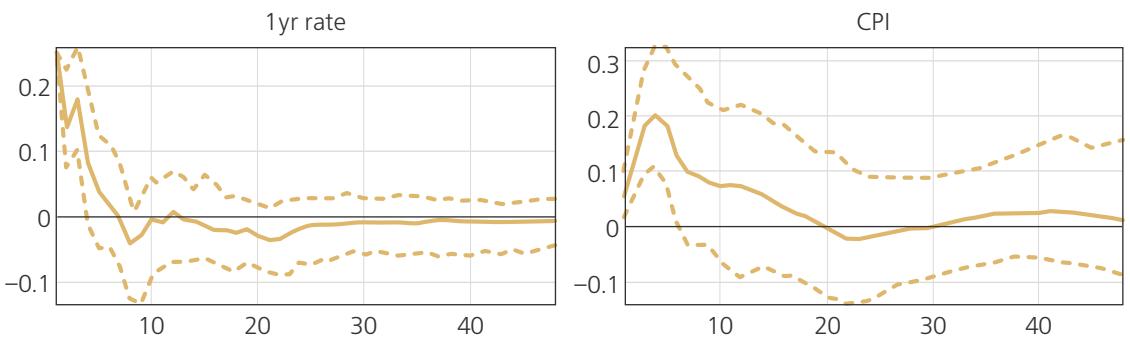

IP
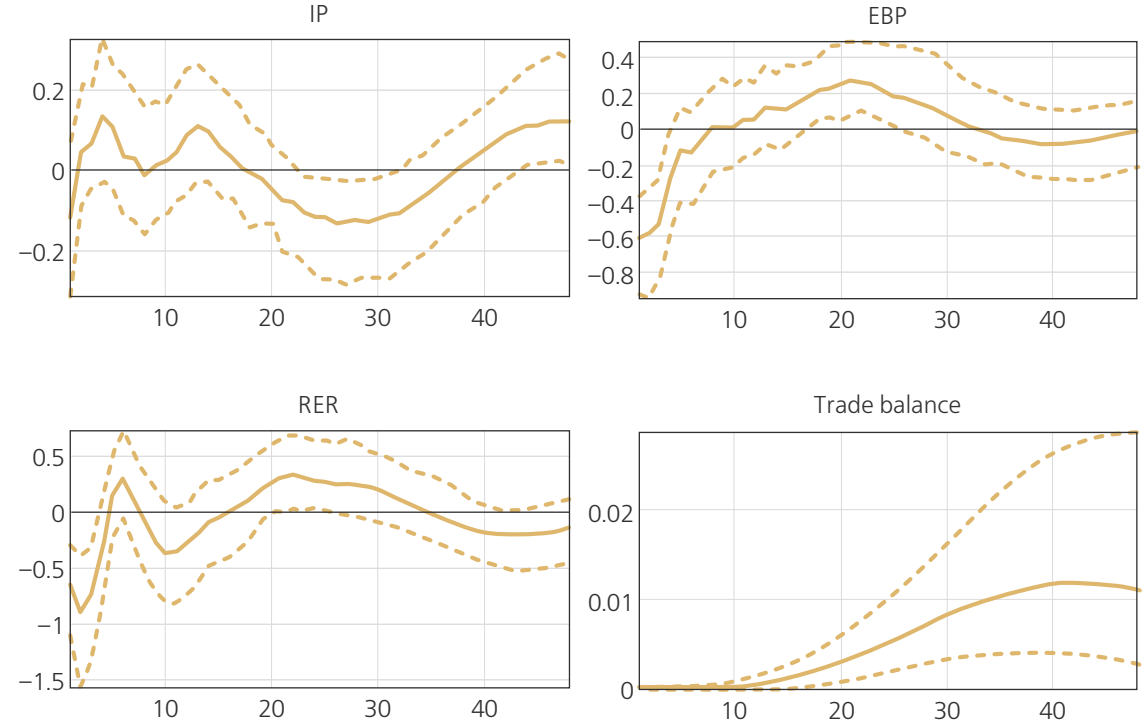

First stage regression, F-stat: 22.68

BIC: -191.39

AIC: -197.36 


\section{Robustness exercise}

The Bank of Russia has only recently begun to target inflation. At the end of 2014, the Bank of Russia switched to an inflation targeting monetary policy, setting a floating exchange rate and a medium-term inflation target at $4 \%$. Therefore, my sample includes periods of different monetary policy regimes.

In this section, I perform two robustness checks. The first one performs sample restrictions, the second one sets 'artificial' dates of monetary policy decision change.

\subsection{Restricted sample}

In this exercise, I restrict my sample to a period ending in summer 2014 (the last period is June 2014). The end of 2014 marks a change of two very different monetary policy regimes: the managed float exchange rate and inflation targeting.

Figure 8. Restricted sample, Cholesky and USD/RUB FX

(a) Cholesky decomposition

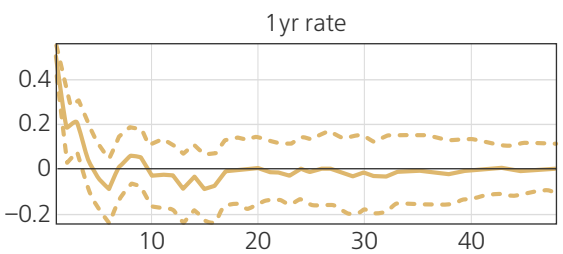

CPI

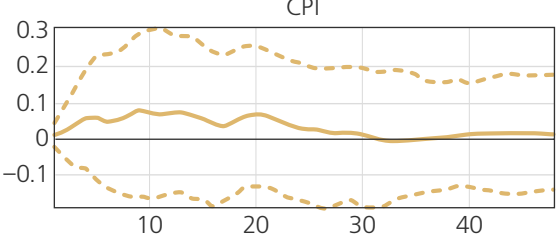

IP
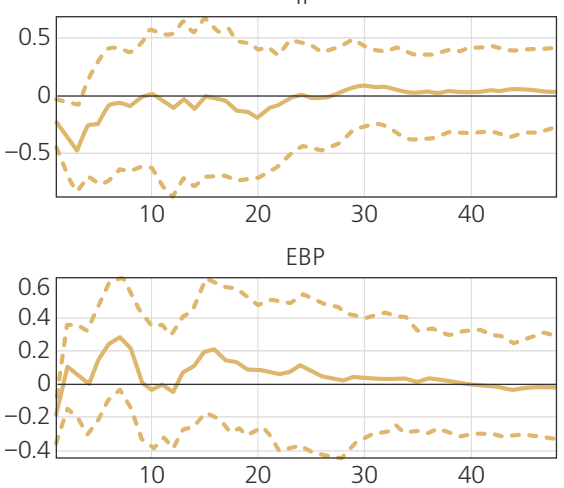

(b) USD/RUB FX
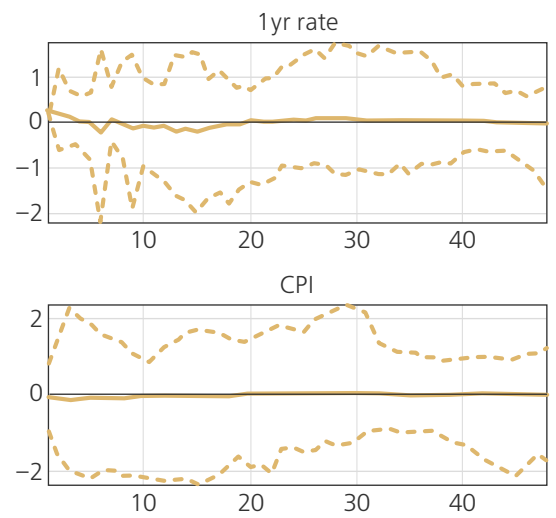

IP

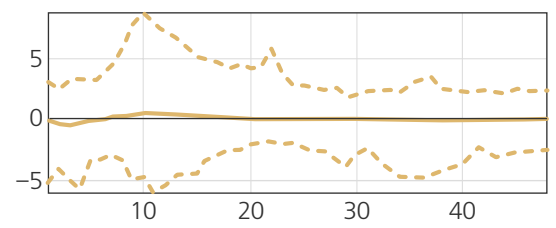

EBP

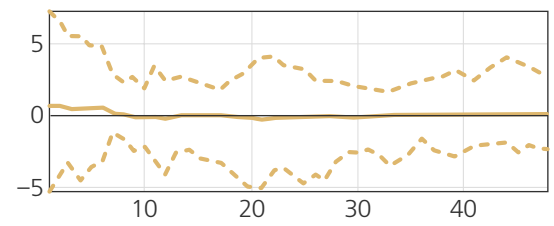

First stage regression, F-stat: 0.43

BIC: -159.21

AIC: -164.67 
In Figure 8 you can see the $\mathcal{J} \mathcal{R} \mathcal{F}$ s for Cholesky decomposition (8a) and USD/RUB spot exchange rate (8b). Here, the results are completely different from the full sample. We do not have any significant results. The $\mathcal{J} \mathcal{R} \mathcal{F}$ s are zero practically everywhere. Moreover, the results are the same with other instruments.

Before 2014 the Bank of Russia pursued a managed floating band exchange rate. Although the band width expanded over time, ${ }^{5}$ the key rate itself did not play a significant role in monetary policy. At the same time, the Bank of Russia used the refinancing rate in its monetary policy (together with different rates for Bank of Russia transactions). Therefore, the refinancing rate played a less important role in monetary policy. Finally, the key rate was introduced only in September 2013. Until January 2016, both rates existed simultaneously. Thus, we can expect to see the effects only after 2014, when the Bank of Russia officially committed to inflation targeting and the key rate became the most important tool in the monetary policy.

\subsection{Change the date}

The second exercise concerns the identification of the day of the monetary policy event. I reestimate the baseline model but instead of the day $t$, the day when the meeting took place, I choose $t-1$ and $t+1$ days. To capture the changes in investors' expectations, I use USD/RUB three-month ahead futures. In this case, I expect that the calculated 'surprises' will not show any responses.

In Figure 9 you can see the results, on the left (9a) you can see the IRFs for one day after the meeting and on the right (9b) you can see the IRFs for one day before the meeting.

We see that there are no responses after the decision. However, one day before the meeting, the $\mathcal{J} \mathcal{R} \mathcal{F}$ s are very similar to the $\mathcal{J} \mathcal{R} \mathcal{F}$ s, for example, in Figure 4 . The movements of all macroeconomic indicators coincide with the movements on the day of the Board of Directors meeting. The F-statistic is also very high.

One of the possible explanations is the following. Either on the day of the meeting the monetary policy surprise is too small and insignificant for the market participants, or the market participants understand the future decision and change their expectations about future prices accordingly. In other words, I cannot distinguish surprises on the day $t$ and $t-1$ because they have very similar $\mathcal{J} \mathcal{R} \mathcal{F}$ s. This poses new questions about the effects of monetary policy decisions on the financial market.

Unfortunately, these robustness exercises do not increase confidence in the obtained results. In my opinion, the question about the transmission mechanism under the managed floating exchange rate regime is debatable, and it requires further study. The second date-falsification exercise does not show robustness. We obtain almost the same responses for two different policy meeting dates.

\footnotetext{
${ }^{5}$ See Parameters of the Bank of Russia FX policy mechanism https://www.cbr.ru/eng/hd_base/valintbr/sp_fxpm_new/
} 
Figure 9. Robustness check, USD/RUB three-month futures

(a) 1 day after

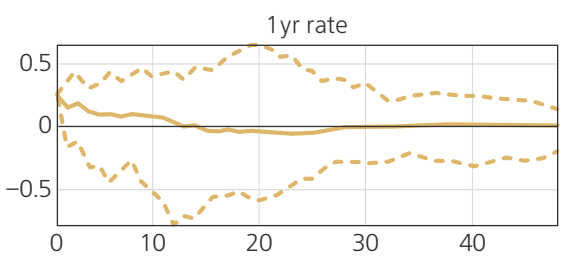

CPI

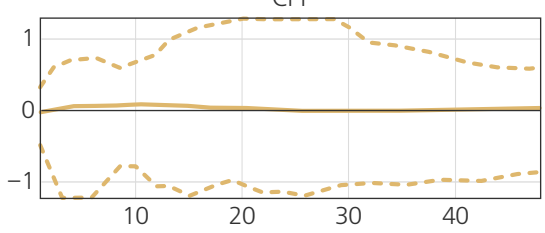

IP

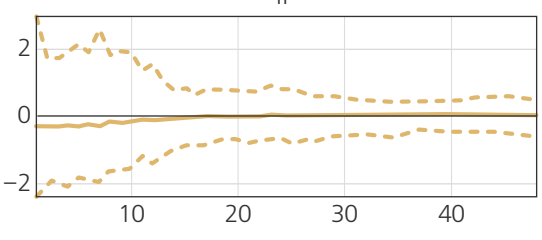

EBP

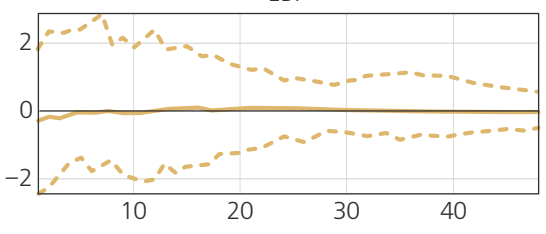

First stage regression, F-stat: 0.67

BIC: -336.93

AIC: -343.30 (b) 1 day before
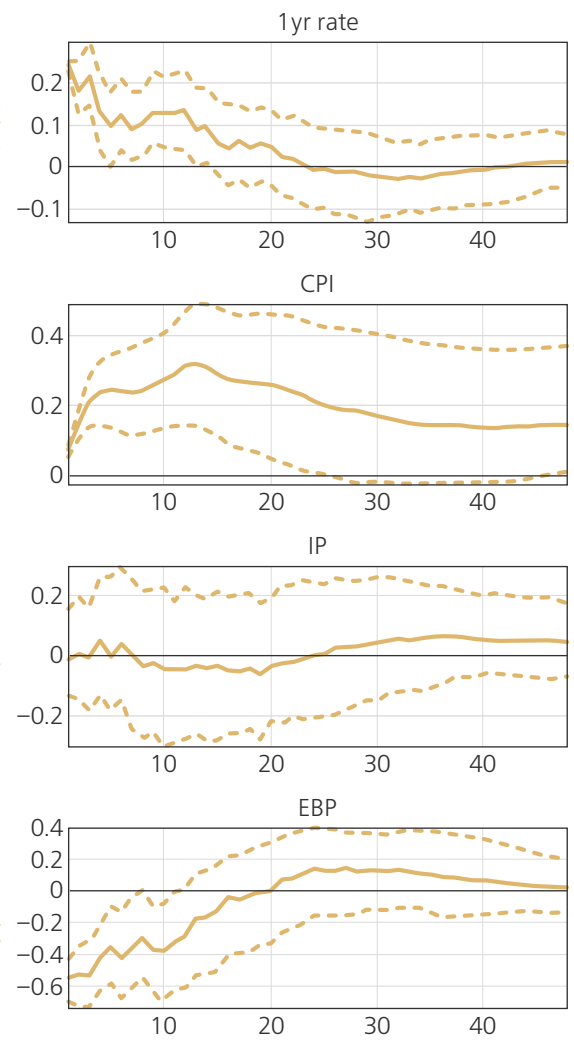

First stage regression, F-stat: 34.52

BIC: -305.73

AIC: -312.09

\section{Conclusion}

The bottom line of this research about Russia is the following. First, I collect the dates of publication of monetary policy decisions by the Bank of Russia from 2008 to 2018. Second, I construct a new series of monetary policy surprises for Russia. Then, I use an external instruments approach, which allows me to obtain exogenous monetary policy shocks on the intraday data and the daily data. Finally, I estimate SVAR models on the Russian data.

Instead of interest rate instruments which are not available for Russia, I use different currency instruments. I find that the one-year government bond rate increases in response to tightening monetary policy. The EBP decreases, which contradicts economic theory (however, there may be problems with the 
measurement of EBP). The CPI shows an inverse $\mathrm{U}$-shape reaction. This response of the CPI may be due to a non-immediate response to the tightening monetary policy. Moreover, I expand this framework to cover a small open economy and find that the results coincide with the baseline specification. Tightening monetary policy increases the trade balance and depreciates the RER.

Unfortunately, these models do not show robust results. The monetary policy under the managed floating exchange rate regime does not show any significant results. This may be due to a different type of monetary policy in which the interest rate plays a less important role. Also, the falsification of the date of the policy decision only brings about new questions.

Nevertheless, I think that this analysis about Russia is useful. Although the results lack robustness, we can still learn something new about the monetary policy transmission mechanism in Russia. Finally, the research poses some questions that require further study.

\section{References}

Adrian, T., Laxton, D. and Obstfeld, M., eds. (2018). Advancing the Frontiers of Monetary Policy. Washington, DC: International Monetary Fund.

Bank of Russia (2018). Monetary Policy Decisions. [Online]. Available at: https://www.cbr.ru/eng/DKP/dkp_press/ [accessed on 25 December 2018].

Cesa-Bianchi, A. (2015). A Toolbox for VAR Analysis. [Online]. Available at: https://sites.google.com/site/ambropo/MatlabCodes [accessed on 25 December 2018].

Cesa-Bianchi, A., Thwaites, G. and Vicondoa, A. (2016). Monetary Policy Transmission in an Open Economy: New Data and Evidence from the United Kingdom. Bank of England Staff Working Paper, N 615.

Cieslak, A. and Schrimpf, A. (2019). Non-Monetary News in Central Bank Communication. Journal of International Economics, 118, pp. 293-315. doi: 10.1016/j.jinteco.2019.01.012

Datastream (2018). Thomson Reuters Datastream. [Online]. Available at: Subscription Service [accessed on 25 December 2018].

Federal State Statistics Service (2018). Main Indicators. [Online]. Available at: http://www.rosstat.gov.ru/wps/wcm/connect/rosstat_main/rosstat/en/ main/ [accessed on 23 October 2019].

Ferrari, M., Kearns, J. and Schrimpf, A. (2016). Monetary Shocks at High-Frequency and Their Changing FX Transmission Around the Globe. Available at SSRN: https://ssrn.com/abstract=2833106 [accessed on 25 December 2018].

Finam (2018). Intra-Day Futures Data. [Online]. Available at: https://www.finam.ru/quotes/futures/ [accessed on 25 December 2018].

Gertler, M. and Karadi, P. (2015). Monetary Policy Surprises, Credit Costs, and Economic Activity. American Economic Journal: Macroeconomics, 7(1), pp. 44-76. doi: $10.1257 / \mathrm{mac} .20130329$ 
Gilchrist, S. and Zakrajšek, E. (2012). Credit Spreads and Business Cycle Fluctuations. American Economic Review, 102(4), pp. 1692-1720. doi: 10.1257/aer.102.4.1692

Gürkaynak, R. S., Sack, B. and Swansonc, E. T. (2005). Do Actions Speak Louder Than Words? The Response of Asset Prices to Monetary Policy Actions and Statements. International Journal of Central Banking, 1(1), pp. 55-93.

International Monetary Fund (2017). Primary Commodity Prices. [Online]. Available at: https://www.imf.org/external/np/res/commod/index.aspx [accessed on 25 December 2018].

Justiniano, A., Evans, C. L., Campbell, J. R. and Fisher, J. D. (2012). Macroeconomic Effects of FOMC Forward Guidance. Brookings Papers on Economic Activity, Spring Edition, pp. 1-80.

Kilian, L. (2011). Structural Vector Autoregressions. CEPR Discussion Papers, N 8515.

Kuttner, K. N. (2001). Monetary Policy Surprises and Interest Rates: Evidence from the Fed Funds Futures Market. Journal of Monetary Economics, 47(3), pp. 523-544. doi: 10.1016/S0304-3932(01)00055-1

Moscow Exchange (2018). Derivatives Market Data. [Online]. Available at: https://www. moex.com/en/derivatives/ [accessed on 25 December 2018].

Nakamura, E. and Steinsson, J. (2018). High Frequency Identification of Monetary Non-Neutrality: The Information Effect. Quarterly Journal of Economics, 133(3), pp. 1283-1330. doi: 10.1093/qje/qjy004

Paul, P. (2019). The Time-Varying Effect of Monetary Policy on Asset Prices. Review of Economics and Statistics. Article in press, pp. 1-44. doi: 10.1162/rest_a_00840

Pescatori, M. A. (2018). Central Bank Communication and Monetary Policy Surprises in Chile. IMF Working Paper, N 156.

Romer, C. D. and Romer, D. H. (2004). A New Measure of Monetary Shocks: Derivation and Implications. American Economic Review, 94(4), pp. 1055-1084. doi: $10.1257 / 0002828042002651$

Stock, J. H. and Watson, M. W. (2016). Dynamic Factor Models, Factor-Augmented Vector Autoregressions, and Structural Vector Autoregressions in Macroeconomics. In: J. B. Taylor, H. Uhlig, eds. Handbook of Macroeconomics. Vol. 2, Elsevier, pp. 415-525.

Stock, J. H. and Yogo, M. (2005). Testing for Weak Instruments in Linear IV Regression. In D. Andrews and J. Stock, eds. Identification and Inference for Econometric Models: Essays in Honor of Thomas Rothenberg. Cambridge: Cambridge University Press, pp. 80-108. doi:10.1017/CBO9780511614491.006

Swanson, E. T. (2017). Measuring the Effects of Federal Reserve Forward Guidance and Asset Purchases on Financial Markets. NBER Working Paper, N 23311.

Zhang, X. (2018). A New Measure of Monetary Policy Shocks. Available at: https://ssrn.com/abstract=3296110 [accessed on 25 December 2018]. 